\title{
Selected characteristics of people on long-term sick leave
}

\author{
Suzanna Rose and Pamela Taylor
}

\begin{abstract}
All personnel within one UK emergency service who had been identified during a six-month period as having been on sick leave for eight consecutive weeks or more were Identified. Those consenting were interviewed once using both a semi-structured questionnaire and standardised instruments. There were three main objectives: to discover the nature of the presenting problem in terms of illness or injury, the extent to which psychological problems presented and the relative importance of general and/or traumatic stressors. The resulting sample of 17 people accounted for 2-3\% of the workforce. Fifteen agreed to take part and 13 to full interview. Of the 14 who completed the Hilton Drinking Behaviour Questionnaire 10 exceeded the threshold consistent with problem drinking. The reason for sick leave in all these cases was recorded as physical injury only.
\end{abstract}

Mental health problems within the working population cost an enormous amount in suffering, loss of performance and money. The latest UK Confederation of British Industry estimate is that stress/depression results in the loss of 24 million working days each year and the estimated cost of this is $£ 1.3$ billion figures, (CBI 1996, further details available from the author upon request). The Health and Safety Executive estimates that $\mathbf{8 0}$ million working days are lost because of mental health problems each year (Health and Safety Executive, 1990). It is widely recognised that stress is a major contributor to absenteeism and sickness absence from work (Banham, 1992). Many people attribute mental health problems to their job (Cherry, 1978, Warr \& Payne, 1988).

There are many potential sources of occupational stress which have been described in the literature (e.g. Crandall \& Perrewe, 1996). Potential general occupational stressors include failure to 'get on' with seniors or colleagues, excessive workload, lack of control of one's work, unreasonable organisation, boring or repetitive tasks and fear of redundancy. There are certain groups who, in addition to more usual occupational stressors, have to cope with traumatic incidents both witnessing injury and death and also risking these eventualities themselves. Fire and rescue, police and ambulance personnel and the armed forces are subject to such events as a regular part of their working lives and there is evidence of possible psychological sequelae for those working in this field (Raphael, 1986; Wilson \& Raphael, 1994; Figley, 1996). Fire and rescue personnel have been noted to be susceptible to general stressors, including organisational pressures (Yu-Chun, 1986; Eliot \& Smith, 1983), as well as more specific traumatic incidents (McFarlane, 1989; McLeod \& Cooper. 1992). Alexander \& Wells (1991) noted that police officers involved with body-handling duties did not suffer from high levels of posttraumatic distress or psychiatric morbidity, but that the subjects described stress-related problems emanating from managerial and organisation issues within the police. There is also considerable literature on similar issues among people in various branches of the armed services (see Taylor et al, 1993 for a brief general introduction to post-traumatic disorders).

This study was designed to discover more about a small subgroup of people in one such public service in the UK which was a complete sample over a six-month period of those who had defined themselves as having major health problems, by taking long-term sick leave. This was defined as absence of work for eight weeks or more in a six-month period. There were three major questions that we wished to explore:

(a) the nature of the presenting problem and accepted reason for sick leave;

(b) the extent to which psychological problems presented overtly, or if not, the extent of psychological comorbidity:

(c) the relative importance of general or organisational and traumatic stressors as background factors.

\section{The study}

The service employed just over 700 people, the substantial majority of whom would at some stage in their work have been faced with major traumatic incidents. A small minority of the employees were women. All staff were approached who had been on sick leave for a continuous period of eight weeks or more during the six months prior to the study. The guidelines 
for selecting the sample were discussed with management, occupational health staff, union representatives and service counsellors, and while a period of eight weeks has no particular medical, financial or psychological significance, it was agreed as being a reasonable period for recovery from illness, beyond which some investigation of underlying causes would be justified. It is a period taken informally in a number of public services as likely to be indicative of progression to chronic absence progressing to financial penalties (services consulted included one emergency service, two National Health Service hospitals and a local authority housing department).

The members of the sample were approached by letter in which the purpose of the study was explained to them, and assurances given regarding confidentiality. They were invited to be interviewed once in their own homes and also asked to complete the standard self-rating schedules listed below.

The standardised self-rating schedules were:

General Health Questionnaire-28 (GHQ; Goldberg \& Hillier, 1979) This is designed as an instrument which detects psychiatric disorder. It concerns itself with two major classes of phenomena: inability to carry out one's normal 'healthy' functions and the appearance of new phenomena of a distressing nature. Scores 0-28, threshold 4-5, more than 5 indicates an underlying health problem.

Impact of Events Scale (IES; Horowitz et al 1979) Score 0-75. Fifteen questions about avoidant and intrusive symptoms of post-traumatic stress disorder (DSM-IV; American Psychiatric Association, 1994): a score of 20 or more is considered clinically significant.

Beck Depression Inventory (BDI; Beck, 1967) Score 0-63. Although designed for American use, in a British study (Metcalfe \& Goldman, 1965) subjects scored similar scores. Thus no depression score $=5$ (mean), mild depression $=14$ (mean), moderate depression $=24$ (mean) and severe depression $=29.5$ (mean)

Hilton Drinking Behaviour Questionnaire (HDBQ; Hilton, 1981) A measure of alcohol drinking behaviour. There is a minimum score of 32 and a maximum of 128 . The questionnaire seeks to distinguish problems rather than normal drinking and therefore scores in excess of 32 indicate some degree of concern in this area.

Life Events Schedule (LES) adapted from Paykel et al, 1969 This was adapted to show life events that had occurred during the last six months. There is no absolute method of scoring the LES, but the nature of events covered is serious (e.g. death in the family, loss of job, marital breakdown), therefore quite a small number of such events in a six-month period would have a cumulative effect.

The interviews were carried out over three months. In addition, use was made of a semistructured questionnaire developed for the study which elicited information regarding demographic data, general physical health and experience of stressors. The data was entered on a computer and analysed using the Statistical Package for the Social Sciences.

\section{Findings}

Seventeen individuals were identified as having been on sick leave from the service for more than eight consecutive weeks in the six-month period studied. That was $2-3 \%$ of the workforce. Of the 17,15 agreed to complete the self-rating scales, 13 were interviewed in addition to this and just two people refused to take any part in the study. Two of the 15 at least partially participating were women.

Among the 15 people who cooperated with the study the majority (10) were married and living with the marital partner, one had separated, two were single and for two information was not available. Only six of the group had children; all of the six were still married. The age range of the group was 22 to 59 , with a mean of 40 , and $60 \%$ of them being between the ages of 30 and 50 . The group was equally divided between long service personnel (seven people) whose commitment had already ranged from 13-29 years, with a mean of 20 years and the recently employed (seven people) in service from one to five years, with a mean of 2.3 years. For only one of these people was the information not known. By the end of the study, three people had negotiated a retirement package.

Although the arbitrary cut off taken for extended sick leave as defined for this study was eight weeks, two-thirds of the sample had been away from work for longer than that. Notably, only two had resolved their sick leave problem by the close of the period under study: one had resumed work but on different, light duties and one had taken early retirement (aged 32, after six months of sick leave).

All the stated reasons for the sick leave related to physical ill health (Table 1). Nevertheless, only a minority of these had to do directly with work. as shown in table. One person who refused interview had back pain and nothing more is known of its origins. The remaining 14 fell into three main groups: three people had had surgery for fully remediable non-related conditions, six had been in non-work related accidents and five 
Table 1. Individual characteristics of personnel on sick leave for more than eight consecutive weeks'

\begin{tabular}{rrrrlll}
\hline $\begin{aligned} \text { Time off } \\
\text { (months) }\end{aligned}$ & GHQ & IES & BDI & HDBQ & LES & Presenting problem \\
\hline 2 & 25 & 64 & 26 & 94 & 8 & Back pain (not interviewed) \\
2 & 8 & 0 & 2 & 32 & 0 & Abdominal problem likely to require surgery \\
16 & 0 & 56 & 11 & 56 & 3 & Back pain, history of injuries at work \\
9 & 1 & 0 & 2 & 59 & 5 & Physical injury not sustained at work \\
4 & 0 & 3 & 0 & 32 & 0 & Physical injury not sustained at work \\
2 & 6 & 0 & 3 & 32 & 2 & Abdominal problem, likely to require surgery \\
2 & 0 & 0 & 0 & 44 & 3 & Back pain, non-work injury \\
12 & 1 & 17 & 3 & 47 & 4 & Back pain, work-related injury \\
15 & 0 & 49 & 6 & 36 & 6 & Back pain, work-related injury \\
4 & 0 & 0 & 0 & 34 & 2 & Abdominal problem likely to require surgery \\
5 & 0 & 19 & 1 & 38 & 3 & Physical injury, not sustained at work \\
6 & 5 & 5 & 5 & 37 & 4 & Back pain, injuries not work-related \\
2 & 0 & 10 & 7 & & 0 & Physical injury work related (not interviewed) \\
11 & 0 & 0 & 1 & 35 & 0 & Back pain, injuries sustained at work \\
5 & 0 & 0 & 0 & 32 & 1 & Physicat injury, sustained at work \\
\hline
\end{tabular}

GHQ, General Health Questionnaire; IES, Impact of Events Scale; BDI, Beck Depression Inventory; HDBQ. Hilton Drinking Behaviour Questionnaire; LES, Life Events Schedule.

1. Two people refused cooperation with the survey.

reported work-related injuries. Most expected to return to work.

One of the principal foci of interest of the study was the extent to which unidentified or undeclared symptoms of stress of other psychological problems were contributing to the extent of sick leave. Neither GHQ nor BDI scores were suggestive of much psychopathology in this group. Just four people reached the cut off point on the GHQ and only one exceeded any of the recognised cutting scores on the BDI (Metcalfe \& Goldman, 1965). Of the people (14) who completed the HDBQ 10 reached the score indicating problem drinking and of these five gained particularly high scores. It may be of interest that of the two partial cooperators, one had the highest score on the HDBQ, not very far from the maximum, and the other refused to complete this questionnaire, possibly suggesting some attempt to conceal problem drinking.

These levels of problem drinking were identified at the time of the study and while the personnel were still on sick leave. They might suggest that one might expect underlying psychological problems, but the semi-structured interview was no more successful than the screening questionnaires in identifying symptomatology. Perhaps in this sense the problem drinking was very effective. Five of the problem drinkers (not necessarily those with the highest scores) had abnormal scores on the IES, suggesting that the individual's experience of traumatic events had had a relevant and important impact for them. The scores for the other subjects suggested that whatever had contributed to their extended sick leave, specific traumatic events were not major contributors.

Part of the semi-structured interview examined, qualitatively, attitudes to working in the service. When asked about the best aspect of the job the words most commonly used by the sample were 'camaraderie' and 'helping people'. Worst aspects were described as boredom. bureaucracy and the dread of serious incidents, especially if children had been involved. When the sample were asked to describe the most stressful part of their job most cited their work with road accidents involving fatalities and three subjects became overly agitated and anxious when recounting their remembered stressful incidents. All of the majority who had been at incidents remembered vividly the first incident at which they encountered a dead body. Three of the sample mentioned the support of experienced and senior colleagues on this occasion as extremely helpful and important.

\section{Comment}

This is a descriptive study of a small group of 17 people giving concern to an organisation employing over 700 people at the time of this study. It can do little more than offer pointers for future work in the field. We know nothing about the two people who refused to cooperate except their long-term sickness status. Of the two who only offered partial cooperation, one appeared to have the most serious psychiatric problems according to responses to the self-rated questionnaires. 
The other did not, and we cannot advance any reason to believe in this case that the injury was anything more than straightforward, although there is a hint of denial in the refusal to participate even in all the self-rated scales.

Probably the most important finding was that 10 of the 14 who completed the HDBQ (of a possible 17) reached the level indicative of problem drinking during their sick leave. The HDBQ (Hilton, 1981) was designed to cover all stages in the development of alcoholism and questions the psychological and physiological consequences of alcohol dependence. The reliability of the questionnaire in terms of internal consistency is high and validity appears satisfactory. While the questionnaire can identify people with alcohol dependence and those at risk in the population, it is undoubtedly true that, given its obvious objective, individuals completing it can give untrue responses and possibly 'fake good'. This could make the scores found even more worrying. There still remains a difficulty with the finding in that it was beyond the scope of this study to establish drinking patterns for those working normally. Given the specifity of the HDBQ, however, we are reasonably confident that this range of scores indicates that at least this small group has special problems.

This study suggests not only that people on long-term sick leave from an occupation which requires physical fitness and tolerance of unusually high emotional stresses among most of its personnel may be particularly prone to excessive alcohol use, but also that this problem in these circumstances may not be explicit to or recognised by the organisation. The value of this observation will depend to some extent on how constructively such an employer would be able to use the information. Honest declaration of possible problems in such an area requires trust that the information will be used to the advantage of the individual as well as the employer. It seems vital information for such an employer when requirement of employees may include driving, at high speeds, and other tasks requiring sharp perception and judgement.

If these findings were to be replicated in a larger sample, with controls not on prolonged sick leave, the all important issue of how to help remains unclear. The general absence of overt psychological problems may just mean that neither interview nor screening questionnaires were sufficiently sensitive. Given, however, the level of experience of stressful events there is a rather ominous possibility that the alcohol use is masking distress and this may be a maintaining factor leaving the group particularly at risk for longer-term drinking unless some intervention is offered. Given the limited scope of this study, the main recommendation is one of highlighting possible alcohol misuse and educating widely within the organisation recognition of the problem, good assessment and the provision of prompt and effective treatment.

The organisation investigated in this study had an occupational health service in place. In this service the occupational health team appeared to place an emphasis on physical health issues. A clinical psychologist was available for consultation, but it was not clear how often this option was taken up. A critical incident stress debriefing and counselling service had been contracted with an outside commercial agency. Providing the external health care team is appropriately qualified, this is likely to be the most effective way forward. The most important factor for employees in taking up mental health services offered by an employer is likely to be anxiety about the consequences of declaring mental health problems. Justification for this anxiety may be regarded as unproven, but it is explicit that the first loyalty of an occupational health service is to the employer, and with the treatability of mental disorders commonly misunderstood employee anxieties may not be misplaced. As there is very little knowledge about provision of optimum services in such situations, would recommend a more substantial study. One important element would be to compare within an organisation those with excellent health records, matched for status in the organisation, with those on long-term sick leave in an attempt to define detector factors and to explore the use and role of the occupational health service. A study of sickness and sick leave between similar - organisations selected for different occupational health policies would provide a natural experiment to test for potentially effective elements in such services.

\section{References}

Alexander, D. A. \& Wells, A. (1991) Reactions of police officers to body-handling after a major disaster. A before and after comparison. British Journal of Psychiatry. 169, 547-555.

AMERICAN PSYCHIATRIC ASSOCIATION (1994) Diagnostic and Statistical Manual of Mental Disorders (4th edn) (DSMIV). Washington, DC: APA.

BANHAM. N. (1992) The cost of mental ill health to business. In Prevention of Mental IIl Health at Work (eds R. Perkins \& N. Coney). London: HMSO.

BECK, A. T. (1967) Depression: Clinical, Experimental and Theoretical Aspects. New York: Paul Hoeber.

CHERRY, N. (1978) Stress, anxiety and work: a longitudinal study. Journal of Occupational Psychology, B1, 259270.

Crandall, R. \& Perrewe, P. (eds) (1996) Occupational Stress: A Handbook. London: Taylor and Francis.

Euor, D. \& SMrrH, D. (1993) Coping with the sharp end: recruitment and selection in the fire service. Disaster Management, 5, 36-40. 
FIGLEY, C. (ed.) (1996) Compassion Fatigue. Coping with Secondary Traumatic Stress Disorder in those Who Treat the Traumatized. New York: Brunner/Mazel.

GolDBERG, D. \& HiLLER, V. F. (1979) A scale version of the General Health Questionnaire. Psychological Medicine. 9. 39-145.

HEALTH AND SAFETY EXECUTIVE (1990) Mental Health at Work (IND (G) 59L). London: HMSO.

HILTON, M. R. (1981) The Hilton Questionnaire: A Measure of Drinking Behaviour. London: NFER-Nelson.

HOROWITZ, M. J. WILNER, N. \& ARVAREZ, W. (1979) Impact of Events Scale: a measure of subjective distress. Psychosomatic Medicine, 41, 207-218.

MCLEOD, J. \& COOPER. D. (1992) A Study of Stress and Support in the Staffordshire Fire and Rescue Service. Keele: Department of Applied Social Studies, University of Keele.

MCFARLANE, A. C. (1989) The aetiology of post-traumatic morbidity: predisposing, precipitating and perpetuating factors. British Joumal of Psychiatry. 154, 221-228.

METCALFE. M. \& Goldman, E. (1965) Validation of an inventory for measuring depression. British Journal of Psychiatry, 111. 240-242.

PAYkel, E. S., MYERS, J. K., Dienelt, M. N., et al (1969) Life events and depression-a controlled study. Archives of General Psychiatry. 21, 753-60.
RAPHAEL, B. (1986) When Disaster Strikes-A Handbook for the Caring Professions. London: Unwin Hyman.

TAYLOR, P., GUNN, J. \& MEZEY, G. (1993) Victim and survivors. In Forensic Psychiatry Clinical, Legal and Ethical Issues (eds P. Taylor \& J. Gunn), pp. 884-944. Oxford: Butterworth-Heinemann.

WARR, P. B. \& PAYNE, R. L. (1988) Experiences of strain and pleasure among British adults. Society. Science and Medicine, 61. 1691-1697.

WILSON, J. \& RAPHAEL, B. (1994) When disaster strikes: managing emotional reactions in rescue workers. In Countertransference in the Treatment of PTSD leds J. Wilson \& J. Lindy). New York: Guilford Press.

YU-CHUN (1986) A study of work stress and illness in Hong Kong fire fighters. Fire Engineers Journal, December. 15-17.

*Suzanna Rose, Clinical Researcher, Department of Psychology. Royal Holloway, University of London, Egham. Surrey TW20 OEX; and Pamela J. Taylor, Professor of Special Hospital Psychiatry, Institute of Psychiatry, London

*Correspondence

\title{
Alcohol and smoking history on admission to a psychiatric hospital
}

\author{
B. Farid, R. H. Bird and B. Naik
}

This is a retrospective study of 173 consecutive admissions to a general psychiatric hospltal. The aim was to establish the frequency and adequacy with which alcohol and tobacco use were recorded. Regarding alcohol, in $41 \%$ of the notes there was no adequate quantitative history, in $29.5 \%$ there was a descripttve mention and in $29.5 \%$ no history was recorded. Female patients were less likely to have an alcohol history taken than male patients. With tobacco, in $64 \%$ of the notes there was an adequate quantitative history, in $6.4 \%$ there was a descriptive comment and in $28.9 \%$ no history was recorded. It is to be stressed to all doctors that an assessment of alcohol and tobacco use should be made for every patient, whatever their age, gender or ethnic origin.

Excess drinking is a major cause of morbidity and mortality in the UK and a common feature of hospital admission and casualty presentation. The Government has specifically targeted excessive drinking in The Health of the Nation, aiming for a reduction in the number currently drinking above the safe limits from 28 to $18 \%$ for males and 11 to $7 \%$ for females by the year 2005 (Department of Health, 1992).

Alcohol has been implicated in the events leading to admission in $23 \%$ of psychiatric patients (Schmidt, 1995) and in 27\% of acute medical admission (Lockhart et al, 1986). Nearly $20 \%$ of psychiatric in-patients have been found to be drinking over eight units a day (Bernadt \& Murray, 1986). Alcohol problems can be a source of interpersonal and public disruption which can increase the probability of being hospitalised (Schmidt, 1995).

Much attention has focused on the failure of doctors to detect excessive drinking among 